\title{
EDAS METHOD FOR MULTIPLE ATTRIBUTE GROUP DECISION MAKING UNDER Q-RUNG ORTHOPAIR FUZZY ENVIRONMENT
}

\author{
Zengxian $\mathrm{LI}^{1}$, Guiwu WEI ${ }^{2 \star}$, Rui $\mathrm{WANG}^{2}$, Jiang $\mathrm{WU}^{3}$, Cun $\mathrm{WEI}^{3}$, Yu WEI ${ }^{4}$ \\ ${ }^{1}$ College of Mathematical Sciences, Sichuan Normal University, Chengdu, 610066, P.R. China \\ ${ }^{2}$ School of Business, Sichuan Normal University, Chengdu, 610101, P.R. China \\ ${ }^{3}$ School of Statistics, Southwestern University of Finance and Economics, Chengdu, 611130, P.R. China \\ ${ }^{4}$ School of Finance, Yunnan University of Finance and Economics, Kunming 650221, China
}

Received 20 February 2019; accepted 15 September 2019

\begin{abstract}
Extended q-rung orthopair fuzzy sets (q-ROFSs) is an excellent tool to depict the qualitative assessing information in multiple attribute group decision making (MAGDM) environments. The EDAS method is very effective especially when the conflicting attributes exist in the MAGDM issues in which the optimal alternative should have the biggest value of PDAS and the smallest value of NDAS. In this paper, we put forward the EDAS method for MAGDM issues under q-ROFSs, which makes use of average solution (AS) for assessing the chosen alternatives. The positive distance from AS (PDAS) and negative distance from AS (NDAS) is derived through the score of q-ROFSs. Then, the sorting order or the optimal alternative can be acquired by computing integrative appraisal score. Finally, a numerical example for buying a refrigerator is given to testify our developed EDAS method and some comparative analysis are also raised to further show the precious merits of this method.
\end{abstract}

Keywords: Multiple attribute group decision making (MAGDM), q-rung orthopair fuzzy sets (qROFSs), EDAS method, q-ROFHA operator, q-ROFHG operator, refrigerator.

JEL Classification: C43, C61, D81.

\section{Introduction}

In recent years, Pythagorean fuzzy sets (PFSs) (Yager, 2014) has appeared as an useful tool for characterizing ambiguity and complexity of the MAGDM(Wang, Gao, \& Wei, 2019; Wu, Wang, \& Gao, 2019). The PFS is depicted by the functions of membership and non-membership, which satisfies the sum of squares of them are limited to 1. Intuitionistic fuzzy sets (IFSs) (Li, Gao, \& Wei, 2018; Wei, 2019; Wu, G. W. Wei, Gao, \& Y. Wei, 2018) are a part of the PFSs (Li, Wei, \& Gao, 2018; Li, Wei, \& Lu, 2018; Peng \& Dai, 2017), which means the PFS is more useful to solve the MAGDM. Moreover, according to the PFSs, Yager (2017) further

${ }^{\star}$ Corresponding author. E-mail: weiguiwu1973@sicnu.edu.cn

This is an Open Access article distributed under the terms of the Creative Commons Attribution License (http://creativecommons. $\mathrm{org} / \mathrm{licenses} / \mathrm{by} / 4.0 /$ ), which permits unrestricted use, distribution, and reproduction in any medium, provided the original author and source are credited. 
designed the q-rung orthopair fuzzy sets (q-ROFSs), each element in q-ROFSs satisfies the sum of the qth power of membership function and non-membership function is less or equal to 1(Wang et al., 2019; P. Wang, J. Wang, G. W. Wei, \& C. Wei, 2019; Wei, Wei, Wang, Gao, \& Wei, 2019). Liu and Wang (2018) defined two q-rung orthopair fuzzy aggregation operators for solving MADM under q-ROFSs. P. D. Liu and J. L. Liu (2018) developed some Bonferroni mean operators under q-ROFSs. Yang and Pang (2019) presented the partitioned Bonferroni mean operators under q-ROFSs. G. W. Wei, C. Wei, Wang, J., Gao, H., \& Y. Wei (2019) extended the MSM and dual MSM (DMSM) operators (Wang, Wei, \& Gao, 2018) to q-ROFSs. Bai, Zhu, Wang, and Zhang (2018) defined the partitioned MSM operator under q-ROFSs. G. W. Wei, Gao, and Y. Wei (2018) studied the generalized Heronian mean (HM) operator with q-ROFNs to handle MAGDM problems. Peng, Dai, and Garg (2018) defined the new score function and exponential operational laws about q-ROFNs.

Keshavarz Ghorabaee, Zavadskas, Olfat, and Turskis (2015) firstly defined the original EDAS to solve many MADM problems. The EDAS method is very effective especially when the conflicting criteria exist in the MADM problem. Similar to VIKOR method (Mirghafoori, Izadi, \& Daei, 2018) and TOPSIS method (Liang, Xu, Liu, \& Wu, 2018), some classical distances are also derived for EDAS method. However, EDAS method should be calculated as PDAS (Positive Distance from Average Solution) and NDAS (Negative Distance from Average Solution) on the basis of AS(average solution). The best alternative should have the biggest value of PDAS and the smallest value of NDAS (Keshavarz Ghorabaee, Zavadskas, Amiri, \& Turskis, 2016). Kahraman et al. (2017) built EDAS method under IFSs. Keshavarz Ghorabaee, Amiri, Zavadskas, and Turskis (2017) analyzed the interval type-2 fuzzy EDAS method. Keshavarz Ghorabaee, Amiri, Zavadskas, Turskis, and Antucheviciene (2017) applied the EDAS method to stochastic MADM. Stanujkic, Zavadskas, Keshavarz Ghorabaee, and Turskis (2017) extended the EDAS method to grey numbers. Karabasevic, Zavadskas, Stanujkic, Popovic, and Brzakovic (2018) proposed the EDAS method with SWARA. Keshavarz-Ghorabaee, Amiri, Zavadskas, Turskis, and Antucheviciene (2018) developed EDAS method in dynamic MCGDM. Stevic, Vasiljevic, Zavadskas, Sremac, and Turskis (2018) designed one of the newer methods-multicriteria analysis of fuzzy EDAS method to choose the most suitable manufacturer of PVC carpentry for the apartment refurbishing.

From above analysis, it's shown that EDAS methods with q-ROFNs to solve MADM don't exist. The goal of this paper is to build q-ROFN-EDAS model and to buy a refrigerator in order to cope with sudden power outages. The rest of this manuscript can be structured as below: some basic knowledge of q-ROFNs is reviewed in section 1. The EDAS method for MAGDM with q-ROFNs is established in Section 2. A numerical example for buying a refrigerator has been given to illustrate this method in Sections 3 and 4 . The last section gives some conclusions.

\section{Preliminaries}

\section{1. q-rung orthopair fuzzy sets}

Yager (2017) defined the q-rung orthopair fuzzy sets (q-ROFSs) as below.

Definition 1 (Yager, 2017). Let $T$ be a fixed set. A q-ROFS Mcan be given as:

$$
M=\left\{\left\langle T, \mu_{M}(t), v_{M}(t)\right\rangle \mid t \in T\right\},
$$


where the function $\mu_{M}(t): M \rightarrow[0,1]$ is the membership degree and the function $v_{M}(t): M \rightarrow[0,1]$ is the non-membership degree, moreover, for every $t \in T$, it satisfies:

$$
\left(\mu_{M}(t)\right)^{q}+\left(v_{M}(t)\right)^{q} \leq 1 .
$$

In addition, the degree of hesitancy is defined as $\pi_{M}(t)=\sqrt[q]{\left(1-\left(\mu_{M}(t)\right)^{q}-\left(v_{M}(t)\right)^{q}\right)}$. Definition 2 (Yager, 2017). Let $M=\left(\mu_{M}, v_{M}\right)$ be a q-ROFN, a score value $S$ is:

$$
S(M)=\left(\mu_{M}(t)\right)^{q}-\left(v_{M}(t)\right)^{q}, S(M) \in[-1,1] .
$$

Definition 3 (Liu \& Wang, 2018). Let $M=\left(\mu_{M}, v_{M}\right)$ be a q-ROFN, an accuracy value $H$ is:

$$
H(M)=\left(\mu_{M}(t)\right)^{q}+\left(v_{M}(t)\right)^{q}, H(M) \in[0,1]
$$

to assess the accuracy of the q-ROFN $M=\left(\mu_{M}, v_{M}\right)$.

Definition 4 (Liu \& Wang, 2018). Let $M_{1}=\left(\mu_{M_{1}}, v_{M_{1}}\right)$ and $M_{2}=\left(\mu_{M_{2}}, v_{M_{2}}\right)$ be two q-ROFNs, $S\left(M_{1}\right)=\left(\mu_{M_{1}}(t)\right)^{q}-\left(v_{M_{1}}(t)\right)^{q}$ and $S\left(M_{2}\right)=\left(\mu_{M_{2}}(t)\right)^{q}-\left(v_{M_{2}}(t)\right)^{q}$ are scores of $M_{1}$ and $M_{2}, H\left(M_{1}\right)=\left(\mu_{M_{1}}(t)\right)^{q}+\left(v_{M_{1}}(t)\right)^{q}$ and $H\left(M_{2}\right)=\left(\mu_{M_{2}}(t)\right)^{q}+\left(v_{M_{2}}(t)\right)^{q}$ are accuracy value of $M_{1}$ and $M_{2}$. Then, if $S\left(M_{1}\right)<S\left(M_{2}\right)$, then $M_{1}<M_{2} ;$ if $S\left(M_{1}\right)=S\left(M_{2}\right)$, then (1) if $H\left(M_{1}\right)=H\left(M_{2}\right)$, then $M_{1}=M_{2} ;(2)$ if $H\left(M_{1}\right)>H\left(M_{2}\right)$, then $M_{1}>M_{2}$.

Definition 5 (Yager, 2017). Let $M_{1}=\left(\mu_{M_{1}}, v_{M_{1}}\right)$ and $M_{2}=\left(\mu_{M_{2}}, v_{M_{2}}\right)$ be two q-ROFNs. Then,

$$
\begin{aligned}
& M_{1} \oplus M_{2}=\left(\sqrt[q]{\left(\mu_{M_{1}}\right)^{q}+\left(\mu_{M_{2}}\right)^{q}-\left(\mu_{M_{1}}\right)^{q}\left(\mu_{M_{2}}\right)^{q}}, v_{M_{1}} v_{M_{2}}\right) \\
& M_{1} \otimes M_{2}=\left(\mu_{M_{1}} \mu_{M_{2}}, \sqrt[q]{\left(v_{M_{1}}\right)^{q}+\left(v_{M_{2}}\right)^{q}-\left(v_{M_{1}}\right)^{q}\left(v_{M_{2}}\right)^{q}}\right) \\
& k M_{1}=\left(\sqrt[k]{1-\left(1-\left(\mu_{M_{1}}\right)^{q}\right)^{k}},\left(v_{M_{1}}\right)^{k}\right) ; \\
& M_{1}^{k}=\left(\left(\mu_{M_{1}}\right)^{k}, \sqrt[q]{1-\left(1-\left(v_{M_{1}}\right)^{q}\right)^{k}}\right) .
\end{aligned}
$$

Example 1. Let $M_{1}=(0.6,0.3), M_{2}=(0.7,0.4), M_{3}=(0.5,0.2)$ be three q-ROFNs $(q=3, k=2)$, according to Definitions 5 , we can get

$$
\begin{aligned}
& M_{1} \oplus M_{2}=\left(\sqrt[3]{0.6^{3}+0.7^{3}-0.6^{3} \times 0.7^{3}}, 0.3^{3} \times 0.4^{3}\right)=(0.7856,0.0017) \\
& M_{1} \otimes M_{2}=\left(0.6^{3} \times 0.7^{3}, \sqrt[3]{0.3^{3}+0.4^{3}-0.3^{3} \times 0.4^{3}}\right)=(0.0741,0.4469) \\
& 2 M_{3}=\left(\sqrt[3]{1-\left(1-0.5^{3}\right)^{2}}, 0.2^{2}\right)=(0.6166,0.0400) \\
& \left(M_{3}\right)^{2}=\left(0.5^{2}, \sqrt[3]{1-\left(1-0.2^{3}\right)^{2}}\right)=(0.2500,0.2516)
\end{aligned}
$$




\section{2. q-rung orthopair fuzzy aggregation operators}

Liu and Wang (2018) defined the q-rung orthopair fuzzy WA ( $q$-ROFWA) operator and the q-rung orthopair fuzzy WG ( $q$-ROFWG) operator.

Definition 6 (Liu \& Wang, 2018). Let $M_{l}=\left(\mu_{M_{l}}, v_{M_{l}}\right)(l=1,2, \cdots, n)$ be a set of q-ROFNs, and q-ROFWA is defined:

$$
\begin{aligned}
& \text { q-ROFWA } \vartheta\left(M_{1}, M_{2}, \cdots, M_{n}\right)=\vartheta_{1} M_{1} \oplus \vartheta_{2} M_{2} \oplus \cdots \oplus \vartheta_{n} M_{n}= \\
& \left(\sqrt[q]{1-\prod_{l=1}^{n}\left(1-\left(\mu_{M_{l}}\right)^{q}\right)^{\vartheta_{l}}}, \prod_{l=1}^{n}\left(v_{M_{l}}\right)^{\vartheta_{l}}\right),
\end{aligned}
$$

where $\vartheta=\left(\vartheta_{1}, \vartheta_{2}, \cdots, \vartheta_{n}\right)^{T}$ is the weight of $M_{l}(l=1,2, \cdots, n)$, with $M_{l} \in[0,1](l=1,2, \cdots, n)$ and $\sum_{l=1}^{n} \vartheta_{l}=1$.

Definition 7. Let $M_{l}=\left(\mu_{M_{l}}, v_{M_{l}}\right)(l=1,2, \cdots, n)$ be a set of q-ROFNs, and q-ROFWG is defined:

$$
\begin{aligned}
& \text { q-ROFWG }{ }_{\vartheta}\left(M_{1}, M_{2}, \cdots, M_{n}\right)=M_{1}^{\vartheta_{1}} \otimes M_{2}^{\vartheta_{2}} \otimes \cdots \otimes M_{n}^{\vartheta_{n}}= \\
& \left(\prod_{l=1}^{n}\left(\mu_{M_{l}}\right)^{\vartheta_{l}}, \sqrt[q]{1-\prod_{l=1}^{n}\left(\left(\mu_{M_{l}}\right)^{q}\right)^{\vartheta_{l}}}\right),
\end{aligned}
$$

where $\vartheta=\left(\vartheta_{1}, \vartheta_{2}, \cdots, \vartheta_{n}\right)^{T}$ is the weight of $M_{l}(l=1,2, \cdots, n)$, with $M_{l} \in[0,1](l=1,2, \cdots, n)$ and $\sum_{l=1}^{n} \vartheta_{l}=1$.

Example 2. Let $M_{1}=(0.8,0.5), M_{2}=(0.7,0.3), M_{3}=(0.6,0.4), M_{4}=(0.9,0.1)$ be four q-ROFNs, and $\vartheta=(0.2,0.4,0.1,0.3)$ is the weight vector of $M_{l}(l=1,2,3,4)$, according to Definitions 6-7, we can get $(q=3)$ :

$$
\begin{aligned}
& \text { q-ROFWA }{ }_{\vartheta}\left(M_{1}, M_{2}, M_{3}, M_{4}\right)=\left(\sqrt[3]{1-\prod_{l=1}^{4}\left(1-\left(\mu_{M_{l}}\right)^{3}\right)^{\vartheta_{l}}}, \prod_{l=1}^{4}\left(v_{M_{l}}\right)^{\vartheta_{l}}\right)= \\
& \left(\begin{array}{l}
\left.\sqrt[3]{1-\left(1-0.8^{3}\right)^{0.2} \times\left(1-0.7^{3}\right)^{0.4} \times\left(1-0.6^{3}\right)^{0.1} \times\left(1-0.9^{3}\right)^{0.3}},\right)=(0.8025,0.2460) \\
0.5^{0.2} \times 0.3^{0.4} \times 0.4^{0.1} \times 0.1^{0.3}
\end{array}\right) \\
& \text { q-ROFWG }\left(M_{1}, M_{2}, M_{3}, M_{4}\right)=\left(\prod_{l=1}^{4}\left(\mu_{M_{l}}\right)^{\vartheta_{l}}, \sqrt[3]{1-\prod_{l=1}^{4}\left(\left(v_{M_{l}}\right)^{3}\right)^{\vartheta_{l}}}\right)= \\
& \left(\begin{array}{l}
0.8^{0.2} \times 0.7^{0.4} \times 0.6^{0.1} \times 0.9^{0.3}, \\
\left.\sqrt[3]{1-\left(1-0.5^{3}\right)^{0.2} \times\left(1-0.3^{3}\right)^{0.4} \times\left(1-0.4^{3}\right)^{0.1} \times\left(1-0.1^{3}\right)^{0.3}}\right)=(0.7634,0.3519)
\end{array}\right.
\end{aligned}
$$

On the basis of the definition 6-7, we shall give some other aggregating operators with q-ROFNs. 
Definition 8. Let $M_{l}=\left(\mu_{M_{l}}, v_{M_{l}}\right)(l=1,2, \cdots, n)$ be a set of q-ROFNs, and q-rung orthopair fuzzy OWA (q-ROFOWA) operator is defined:

$$
\begin{aligned}
& \text { q-ROFOWA }{ }_{\theta}\left(M_{1}, M_{2}, \cdots, M_{n}\right)=\theta_{1} M_{\rho(1)} \oplus \theta_{2} M_{\rho(2)} \oplus \cdots \oplus \theta_{n} M_{\rho(n)}= \\
& \left(\sqrt[q]{1-\prod_{l=1}^{n}\left(1-\left(\mu_{M_{\rho(l)}}\right)^{q}\right)^{\theta_{l}}}, \prod_{l=1}^{n}\left(v_{M_{\rho(l)}}\right)^{\theta_{l}}\right)
\end{aligned}
$$

where $\theta=\left(\theta_{1}, \theta_{2}, \cdots, \theta_{n}\right)^{T}$ is the position weights, with $M_{l} \in[0,1](l=1,2, \cdots, n)$ and $\sum_{l=1}^{n} \theta_{l}=1$, and $(\rho(1), \rho(2), \cdots, \rho(n))$ is a permutation of $(1,2, \cdots, n)$, such that $M_{\rho(l-1)}>M_{\rho(l)}$, for any $l$.

Definition 9. Let $M_{l}=\left(\mu_{M_{l}}, v_{M_{l}}\right)(l=1,2, \cdots, n)$ be a set of q-ROFNs, and q-rung orthopair fuzzy OWG (q-ROFOWG) operator is defined:

$$
\begin{aligned}
& \text { q-ROFOWG }{ }_{\theta}\left(M_{1}, M_{2}, \cdots, M_{n}\right)=M_{\rho(1)}^{\theta_{1}} \otimes M_{\rho(2)}^{\theta_{2}} \otimes \cdots \otimes M_{\rho(n)}^{\theta_{n}}= \\
& \left(\prod_{l=1}^{n}\left(\mu_{M_{\rho(l)}}\right)^{\theta_{l}}, \sqrt[q]{1-\prod_{l=1}^{n}\left(1-\left(v_{M_{\rho(l)}}\right)^{q}\right)^{\theta_{l}}}\right),
\end{aligned}
$$

where $\theta=\left(\theta_{1}, \theta_{2}, \cdots, \theta_{n}\right)^{T}$ is the position weights, with $M_{l} \in[0,1](l=1,2, \cdots, n)$ and $\sum_{l=1}^{n} \theta_{l}=1$,

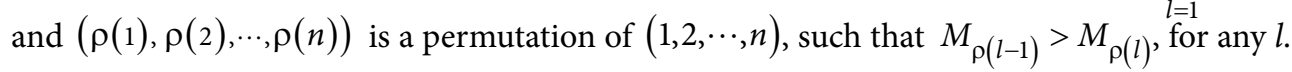
Example 3. Let $M_{1}=(0.7,0.2), M_{2}=(0.6,0.5), M_{3}=(0.9,0.3), M_{4}=(0.8,0.4)$ be four qROFNs, according to Definitions $2-3$, we can get $(q=3)$ :

$$
\begin{aligned}
& S\left(M_{1}\right)=0.7^{3}-0.2^{3}=0.3350, S\left(M_{2}\right)=0.6^{3}-0.5^{3}=0.0910 \\
& S\left(M_{3}\right)=0.9^{3}-0.3^{3}=0.7020, S\left(M_{4}\right)=0.8^{3}-0.4^{3}=0.4480 .
\end{aligned}
$$

Since $S\left(M_{3}\right)>S\left(M_{4}\right)>S\left(M_{1}\right)>S\left(M_{2}\right)$, we have $M_{\rho(1)}=(0.9,0.3), M_{\rho(2)}=(0.8,0.4)$, $M_{\rho(3)}=(0.7,0.3), M_{\rho(4)}=(0.6,0.5)$ and $\theta=(0.3,0.1,0.2,0.4)$ is the weighted vector associated with the q-ROFOWA and q-ROFOWG operators. Then, according to Definitions 8-9, we can get:

$$
\begin{aligned}
& \text { q-ROFOWA } \theta\left(M_{1}, M_{2}, M_{3}, M_{4}\right)=\left(\sqrt[3]{1-\prod_{l=1}^{4}\left(1-\left(\mu_{M_{\rho}(l)}\right)^{3}\right)^{\theta_{l}}}, \prod_{l=1}^{4}\left(1-\mu_{M_{\rho}(l)}\right)^{\theta_{l}}\right)= \\
& \left(\begin{array}{l}
\left.\sqrt[3]{1-\left(1-0.9^{3}\right)^{0.3} \times\left(1-0.8^{3}\right)^{0.1} \times\left(1-0.7^{3}\right)^{0.2} \times\left(1-0.6^{3}\right)^{0.4}},\right)=(0.7804,0.3788) \\
0.3^{0.3} \times 0.4^{0.1} \times 0.3^{0.2} \times 0.5^{0.4}
\end{array}\right) \\
& \text { q-ROFOWG }{ }_{\theta}\left(M_{1}, M_{2}, M_{3}, M_{4}\right)=\left(\prod_{l=1}^{4}\left(\mu_{M_{\rho}(l)}\right)^{\theta_{l}}, \sqrt[3]{1-\prod_{l=1}^{4}\left(1-\left(v_{M_{\rho}(l)}\right)^{3}\right)^{\theta_{l}}}\right)= \\
& \left(\begin{array}{l}
0.9^{0.3} \times 0.8^{0.1} \times 0.7^{0.2} \times 0.6^{0.4} \\
\left.\sqrt[3]{1-\left(1-0.3^{3}\right)^{0.3} \times\left(1-0.4^{3}\right)^{0.1} \times\left(1-0.3^{3}\right)^{0.2} \times\left(1-0.5^{3}\right)^{0.4}}\right)=(0.7192,0.4142) .
\end{array}\right.
\end{aligned}
$$


From above, we know that q-ROFWA and q-ROFWG operators only take into account the weight of the q-ROFNs, and the q-ROFOWA and q-ROFOWG operators only considers the ordered positions. To consider both weight of the q-ROFNs and the ordered positions, then, we now define q-rung orthopair fuzzy hybrid aggregation (q-ROFHA) and q-rung orthopair fuzzy hybrid geometric (q-ROFHG) operators.

Definition 10. Let $M_{l}=\left(\mu_{M_{l}}, v_{M_{l}}\right)(l=1,2, \cdots, n)$ be a set of q-ROFNs, and q-ROFHA, then

$$
\begin{aligned}
& \text { q-ROFHA }_{\theta, \vartheta}\left(M_{1}, M_{2}, \cdots, M_{n}\right)=\theta_{1} X_{\rho(1)} \oplus \theta_{2} X_{\rho(2)} \oplus \cdots \oplus \theta_{n} X_{\rho(n)}= \\
& \left(\sqrt[q]{1-\prod_{l=1}^{n}\left(1-\left(\mu_{X_{\rho(l)}}\right)^{q}\right)^{\theta_{l}}}, \prod_{l=1}^{n}\left(v_{X_{\rho(l)}}\right)^{\theta_{l}}\right),
\end{aligned}
$$

where $\theta=\left(\theta_{1}, \theta_{2}, \cdots, \theta_{n}\right)^{T}$ is the position weights, with $\theta_{l} \in[0,1](l=1,2, \cdots, n)$ and $\sum_{l=1}^{n} \theta_{l}=1$, $X_{l}=n \vartheta_{l} M_{l},(l=1,2, \cdots, n)$, and $\left(X_{\rho(1)}, X_{\rho(2)}, \cdots, X_{\rho(n)}\right)$ is a permutation of a set of the weighted q-ROFNs $\left(X_{\rho(1)}, X_{\rho(2)}, \cdots, X_{\rho(n)}\right)$, such that $X_{\rho(l-1)}>X_{\rho(l)}$, for any $l ; \vartheta=\left(\vartheta_{1}, \vartheta_{2}, \cdots, \vartheta_{n}\right)^{T}$ is the weight vector of $M_{l}(l=1,2, \cdots, n)$, with $\vartheta_{l} \in[0,1](l=1,2, \cdots, n)$ and $\sum_{l=1}^{n} \vartheta_{l}=1$, and $n$
is the balancing coefficient.

Definition 11. Let $M_{l}=\left(\mu_{M_{l}}, v_{M_{l}}\right)(l=1,2, \cdots, n)$ be a set of q-ROFNs, and q-ROFHG is defined:

$$
\begin{aligned}
& \text { q-ROFHG }{ }_{\theta, \vartheta}\left(M_{1}, M_{2}, \cdots, M_{n}\right)=Y_{\rho(1)}^{\theta_{1}} \otimes Y_{\rho(2)}^{\theta_{2}} \oplus \cdots \oplus Y_{\rho(n)}^{\theta_{n}}= \\
& \left(\prod_{l=1}^{n}\left(\mu_{\hat{M}_{\rho(l)}}\right)^{\theta_{l}}, \sqrt[q]{1-\prod_{l=1}^{n}\left(1-\left(v_{\hat{M}_{\rho(l)}}\right)^{q}\right)^{\theta_{l}}}\right)
\end{aligned}
$$

where $\theta=\left(\theta_{1}, \theta_{2}, \cdots, \theta_{n}\right)^{T}$ is position weights, with $\theta_{l} \in[0,1](l=1,2, \cdots, n)$ and $\sum_{l=1}^{n} \theta_{l}=1$, $Y_{l}=M_{l}^{n \vartheta_{l}},(l=1,2, \cdots, n)$, and $\left(Y_{\rho(1)}, Y_{\rho(2)}, \cdots, Y_{\rho(n)}\right)$ is a permutation of a set of the weighted q-ROFNs $\left(Y_{\rho(1)}, Y_{\rho(2)}, \cdots, Y_{\rho(n)}\right)$, such that $Y_{\rho(l-1)}>Y_{\rho(l)}$, for any $l ; \vartheta=\left(\vartheta_{1}, \vartheta_{2}, \cdots, \vartheta_{n}\right)^{T}$ is the weight vector of $M_{l}(l=1,2, \cdots, n)$, with $\vartheta_{l} \in[0,1](l=1,2, \cdots, n)$ and $\sum_{l=1}^{n} \vartheta_{l}=1$, and $n$ is
the balancing coefficient.

Obviously, from Definition 10-11, we know that the q-ROFHA operator and q-ROFHG operator consists of the following computational steps.

1) First, we give the corresponding weight $\vartheta_{l}(l=1,2, \cdots, n)$ to the q-ROFNs $M_{l}(l=1,2, \cdots, n)$, and get $\vartheta_{l} M_{l}$ or $M_{l}^{\vartheta_{l}}$, then multiply these values by the balance coefficient $n$, and get $n \vartheta_{l} M_{l}$ or $M_{l}^{n \vartheta_{l}}$.

2) Secondly, we reorder the weighted q-ROFNs $X_{l}=n \vartheta_{l} M_{l}$ or $Y_{l}=M_{l}^{n \vartheta}(l=1,2, \cdots, n)$ in descending order $\left(X_{\rho(1)}, X_{\rho(2)}, \cdots, X_{\rho(n)}\right)$ or $\left(Y_{\rho(1)}, Y_{\rho(2)}, \cdots, Y_{\rho(n)}\right)$, where $X_{\rho(l)}$ is the $l$-th largest of $n \vartheta_{l} M_{l}(l=1,2, \cdots, n)$, and $Y_{\rho(l)}$ is the $l$-th largest of $M_{l}^{n \vartheta}$. 
3) Finally, the $X_{\rho(l)}$ or $Y_{\rho(l)}$ is weighted by the ordered weights $\theta_{l} \in[0,1](l=1,2, \cdots, n)$, and then aggregate all the weighted q-ROFNs $\theta_{l} X_{\rho(l)}$ or $\left(Y_{\rho(l)}\right)^{\theta_{l}}$ into the collective ones.

From the above analysis, we can know that: (1) q-ROFWA and q-ROFOWA operators are special cases of q-ROFHA operator; q-ROFWG and q-ROFOWG operators are special cases of the q-ROFHG operator. (2) The q-ROFHA operator generalizes q-ROFWA and qROFOWA operators; the q-ROFHG operator generalizes q-ROFWG and q-ROFOWG operators. (3) The advantages of the q-ROFHA operator and the q-ROFHG operator are that they consider not only the importance of the given q-ROFNs themselves but also the ordered positions of the given q-ROFNs.

Example 4. Let $M_{1}=(0.7,0.2), M_{2}=(0.6,0.3), M_{3}=(0.9,0.1), M_{4}=(0.8,0.2), M_{5}=(0.3,0.7)$ be five q-ROFNs $(q=3)$, and $\vartheta=(0.14,0.20,0.16,0.30,0.20)^{T}$ is the weight vector of $M_{l}(l=1,2,3,4,5)$. According to Definitions 10 , we can get the weighted q-ROFNs:

$$
\begin{aligned}
& X_{1}=5 \times 0.14 \times M_{1}=\left(\sqrt[3]{1-\left(1-0.7^{3}\right)^{5 \times 0.14}},(0.2)^{5 \times 0.14}\right)=(0.6062,0.3807) \\
& X_{2}=5 \times 0.2 \times M_{2}=\left(\sqrt[3]{1-\left(1-0.6^{3}\right)^{5 \times 0.2}},(0.3)^{5 \times 0.2}\right)=(0.6000,0.3000) ; \\
& X_{3}=5 \times 0.16 \times M_{3}=\left(\sqrt[3]{1-\left(1-0.9^{3}\right)^{5 \times 0.16}},(0.1)^{5 \times 0.16}\right)=(0.8842,0.1259) ; \\
& X_{4}=5 \times 0.3 \times M_{4}=\left(\sqrt[3]{1-\left(1-0.8^{3}\right)^{5 \times 0.3}},(0.2)^{5 \times 0.3}\right)=(0.8703,0.0894) ; \\
& X_{5}=5 \times 0.2 \times M_{5}=\left(\sqrt[3]{1-\left(1-0.3^{3}\right)^{5 \times 0.2}},(0.7)^{5 \times 0.2}\right)=(0.3000,0.7000)
\end{aligned}
$$

According to Definitions 2, we can get the score of $X_{l}(l=1,2,3,4,5)$ :

$S\left(X_{1}\right)=0.1676, S\left(X_{2}\right)=0.1890, S\left(X_{3}\right)=0.6892, S\left(X_{4}\right)=0.6584, S\left(X_{5}\right)=-0.3160$.

Since $S\left(X_{3}\right)>S\left(X_{4}\right)>S\left(X_{2}\right)>S\left(X_{1}\right)>S\left(X_{5}\right)$

we have

$$
\begin{aligned}
& X_{\rho(1)}=(0.8842,0.1259), X_{\rho(2)}=(0.8703,0.0894), X_{\rho(3)}=(0.6000,0.3000), \\
& X_{\rho(4)}=(0.6062,0.3807), X_{\rho(5)}=(0.3000,0.7000) .
\end{aligned}
$$

Suppose that $\theta=(0.20,0.15,0.25,0.30,0.10)^{T}$ is the weight of q-ROFHA operator. Then, according to Definitions 10, we can get:

$$
\begin{aligned}
& \text { q-ROFHA }_{\theta, 9}\left(M_{1}, M_{2}, M_{3}, M_{4}, M_{5}\right)=\left(\sqrt[3]{\left.1-\prod_{l=1}^{5}\left(1-\left(\mu_{X_{\rho}(l)}\right)^{3}\right)^{\theta_{l}}, \prod_{l=1}^{5}\left(v_{X_{\rho}(l)}\right)^{\theta_{l}}\right)}=\right. \\
& \left(\begin{array}{l}
\sqrt[3]{\left(1-\left(1-0.8842^{3}\right)^{0.20} \times\left(1-0.8703^{3}\right)^{0.15} \times\right.} \\
\left(1-0.6000^{3}\right)^{0.25} \times\left(1-0.6062^{3}\right)^{0.30} \times\left(1-0.3000^{3}\right)^{0.10}, \\
(0.1259)^{0.20} \times(0.0894)^{0.15} \times(0.3000)^{0.25} \times(0.3807)^{0.30} \times(0.7000)^{0.10}
\end{array}\right)=(0.7569,0.2459) .
\end{aligned}
$$


Meantime, according to Definitions 11, we can get the weighted q-ROFNs:

$$
\begin{aligned}
& Y_{1}=M_{1}^{5 \times 0.14}=\left((0.7)^{5 \times 0.14}, \sqrt[3]{1-\left(1-0.2^{3}\right)^{5 \times 0.14}}\right)=(0.8073,0.1688) ; \\
& Y_{2}=M_{2}^{5 \times 0.2}=\left((0.6)^{5 \times 0.2}, \sqrt[3]{1-\left(1-0.3^{3}\right)^{5 \times 0.2}}\right)=(0.6000,0.3000) ; \\
& Y_{3}=M_{3}^{5 \times 0.16}=\left((0.9)^{5 \times 0.16}, \sqrt[3]{1-\left(1-0.1^{3}\right)^{5 \times 0.16}}\right)=(0.9095,0.0966) ; \\
& Y_{4}=M_{4}^{5 \times 0.3}=\left((0.8)^{5 \times 0.3}, \sqrt[3]{1-\left(1-0.2^{3}\right)^{5 \times 0.3}}\right)=(0.7155,0.2288) ; \\
& Y_{5}=M_{5}^{5 \times 0.2}=\left((0.3)^{5 \times 0.2}, \sqrt[3]{1-\left(1-0.7^{3}\right)^{5 \times 0.2}}\right)=(0.3000,0.7000)
\end{aligned}
$$

According to Definitions 2, we can get the score of $Y_{l}(l=1,2,3,4,5)$ :

$S\left(Y_{1}\right)=0.5214, S\left(Y_{2}\right)=0.1890, S\left(Y_{3}\right)=0.7512, S\left(Y_{4}\right)=0.3544, S\left(Y_{5}\right)=-0.3160$.

Since $S\left(Y_{3}\right)>S\left(Y_{1}\right)>S\left(Y_{4}\right)>S\left(Y_{2}\right)>S\left(Y_{5}\right)$.

We have:

$$
\begin{aligned}
& Y_{\rho(1)}=(0.9095,0.0966), Y_{\rho(2)}=(0.8703,0.1688), Y_{\rho(3)}=(0.7155,0.2288), \\
& Y_{\rho(4)}=(0.6000,0.3000), Y_{\rho(5)}=(0.3000,0.7000) .
\end{aligned}
$$

Suppose that $\theta=(0.20,0.15,0.25,0.30,0.10)^{T}$ is the weight of q-ROFHG operator. Then, according to Definitions 11 , we can get:

$$
\left.\begin{array}{l}
\mathrm{q}-\mathrm{ROFHG}_{\theta, \vartheta}\left(M_{1}, M_{2}, M_{3}, M_{4}, M_{5}\right)=\left(\prod_{l=1}^{5}\left(\mu_{Y_{\rho}(l)}\right)^{\theta_{l}}, \sqrt[3]{1-\prod_{l=1}^{5}\left(1-\left(v_{Y_{\rho}(l)}\right)^{3}\right)^{\theta_{l}}}\right)= \\
\left(\sqrt[3]{(0.9095)^{0.20} \times(0.8703)^{0.15} \times(0.7155)^{0.25} \times(0.6000)^{0.30} \times(0.3000)^{0.10}}\right)=(0.5576,0.4988) . \\
\sqrt[3]{\left(1-0.2288^{3}\right)^{0.25} \times\left(1-0.3000^{3}\right)^{0.30} \times\left(1-0.7000^{3}\right)^{0.10}} \times\left(1-0966^{3}\right)^{0.20} \times\left(1-0.1688^{3}\right)^{0.15} \times
\end{array}\right)=
$$

\section{EDAS method for MAGDM with q-ROFNs}

Let $T=\left(T_{1}, T_{2}, \cdots, T_{m}\right)$ be a set of alternatives, $X=\left(X_{1}, X_{2}, \cdots, X_{n}\right)$ be a group of attributes and $k$ experts $\left\{\phi_{1}, \phi_{2}, \cdots, \phi_{k}\right\}$. Let $\vartheta=\left(\vartheta_{1}, \vartheta_{2}, \cdots, \vartheta_{n}\right)^{T}$ be the attributes' weighting vector, $\rho=\left\{\rho_{1}, \rho_{2}, \cdots, \rho_{k}\right\}$ be the experts' weighting vector, where $\vartheta_{h} \in[0,1](h=1,2, \cdots, n)$, $\rho_{i} \in[0,1](i=1,2, \cdots, k)$ and $\sum_{h=1}^{n} \vartheta_{h}=1, \sum_{i=1}^{k} \rho_{i}=1$. Assume that the attributes $X_{h}$ with respect to alternative $T_{l}$ are assessed by expert $\phi_{i}$ with q-ROFN $e_{h l}^{i}=\left(\mu_{h l}^{i}, v_{h l}^{i}\right)$ $(h=1,2, \cdots, n, l=1,2, \cdots, m, i=1,2, \cdots, k)$. 
On the basis of the conventional EDAS method, the EDAS method for MAGDM with q-ROFNs is proposed. The specific steps are as below:

Step 1: Building the evaluation matrix

$$
E^{i}=\left[e_{h l}^{i}\right]_{n \times m}, h=1,2, \cdots, n, l=1,2, \cdots, m, i=1,2, \cdots, k .
$$

Step 2: According to q-ROFHA or q-ROFHG operator, we can get overall matrix

$$
E=\left(e_{h l}\right)_{n \times m}=\left(\mu_{h l}, v_{h l}\right)_{n \times m}, h=1,2, \cdots, n, l=1,2, \cdots, m .
$$

Step 3: Determine the AS of all the alternatives under each attribute.

$$
\mathrm{AS}=\left(\mathrm{AS}_{1}, \mathrm{AS}_{2}, \cdots, \mathrm{AS}_{n}\right) \text {, }
$$

where $\mathrm{AS}_{h}=\left(\mu_{h}, v_{h}\right)=\frac{1}{m} e_{h 1} \oplus \frac{1}{m} e_{h 2} \oplus \cdots \oplus \frac{1}{m} e_{h m}=$

$$
\left(\sqrt[q]{1-\prod_{l=1}^{m}\left(1-\left(\mu_{h l}\right)^{q}\right)^{\frac{1}{m}}}, \prod_{l=1}^{m}\left(v_{h l}\right)^{\frac{1}{m}}\right)(h=1,2, \cdots, n) .
$$

Step 4: According to different types of attributes, calculate the PDAS matrix and the NDAS matrix.

$$
\begin{aligned}
& \mathrm{PDAS}=\left(\operatorname{PDAS}_{h l}\right)_{n \times m}, \mathrm{NDAS}=\left(\mathrm{NDAS}_{h l}\right)_{n \times m}, \\
& \operatorname{PDAS}_{h l}=\frac{\max \left(0,\left(S\left(e_{h l}\right)-S\left(\mathrm{AS}_{h}\right)\right)\right)}{S\left(\mathrm{AS}_{h}\right)}, \mathrm{NDAS}_{h l}=\frac{\max \left(0,\left(S\left(\mathrm{AS}_{h}\right)-S\left(e_{h l}\right)\right)\right)}{S\left(\mathrm{AS}_{h}\right)},
\end{aligned}
$$

where $S\left(e_{h l}\right), S\left(\mathrm{AS}_{h}\right)$ is the score function.

Step 5: Compute the positive weighted distance $\operatorname{SP}_{l}(l=1,2, \cdots, m)$ and the negative weighted distance $\mathrm{SN}_{l}(l=1,2, \cdots, m)$ :

$$
\mathrm{SP}_{l}=\sum_{h=1}^{n} \vartheta_{h} \mathrm{PDAS}_{h l}, \mathrm{SN}_{l}=\sum_{h=1}^{n} \vartheta_{h} \mathrm{NDAS}_{h l},
$$

where $\vartheta_{h} \in[0,1], \sum_{h=1}^{n} \vartheta_{h}=1$.

Step 6: Normalize the $\operatorname{SP}_{l}(l=1,2, \cdots, m)$ and $\mathrm{SN}_{l}(l=1,2, \cdots, m)$ by following equations:

$$
\mathrm{NSP}_{l}=\frac{\mathrm{SP}_{l}}{\max \left(\mathrm{SP}_{1}, \mathrm{SP}_{2}, \cdots, \mathrm{SP}_{m}\right)}, \mathrm{NSN}_{l}=\frac{\mathrm{SN}_{l}}{\max \left(\mathrm{SN}_{1}, \mathrm{SN}_{2}, \cdots, \mathrm{SN}_{m}\right)},
$$

where $\max \left(\mathrm{SP}_{1}, \mathrm{SP}_{2}, \cdots, \mathrm{SP}_{m}\right)$ and $\max \left(\mathrm{SN}_{1}, \mathrm{SN}_{2}, \cdots, \mathrm{SN}_{m}\right)$ are the maximum distance.

Step 7: Derive the integrative appraisal score $\left(\operatorname{IAS}_{l}\right)(l=1,2, \cdots, m)$ according to equation (19):

where $\mathrm{IAS}_{l} \in[0,1]$.

$$
\mathrm{IAS}_{l}=\frac{1}{2}\left(\mathrm{NSP}_{l}+1-\mathrm{NSN}_{l}\right)
$$

Step 8: Derive the ordering in accordance with the results of $\operatorname{IAS}_{l}(l=1,2, \cdots, m)$. The larger $\operatorname{IAS}_{l}(l=1,2, \cdots, m)$, the better the alternative is. 


\section{Case analysis}

With development of social and improvement of peoples' living standards, the household refrigerator becomes a necessary appliance. The household refrigerator can provide the low temperature for saving food and simultaneously it consumes a lot of energy during 24-hour running. Improving refrigerator performance, not only can contribute to electricity saving for families, but also contributes to the national advocated motivation of energy-saving emission reduction and low-carbon, even contribute to the environment sustainability. Therefore, it is very important for potential customers to make an overall evaluation of alternative refrigerator through qualitative reviews. To facilitate consumer purchase decisions, ranking the alternative refrigerator based on EDAS method is a worthy research topic which is also regards as a classical MAGDM problem. Let us consider a customer who wants to buy a refrigerator. There are five kinds of possible refrigerators $T_{l}(l=1,2,3,4,5)$ are available. The customer pay attention to six attributes to decide which kind of refrigerator to buy:(1) $X_{1}$-safety, (2) $X_{2}$-refrigeration performance, (3) $X_{3}$-design, (4) $X_{4}$-reliability, (5) $X_{5}$-economic, (6) $X_{6}$-aesthetics. All these attributes are beneficial attributes and $\vartheta=(0.20,0.15,0.25,0.17,0.13,0.10)$ is the weight of $X_{h}(h=1,2,3,4,5,6)$. Three experts evaluate the refrigerator $T_{l}(l=1,2,3,4,5)$ in accordance with $X_{h}(h=1,2,3,4,5,6)$ by q-ROFNs, and form the decision matrix with qROFNs (see Tables $1-3$ ), and expert weighting vector is $\rho=(0.3,0.3,0.4)$.

Table 1. Decision matrix with q-ROFNs by the first expert

\begin{tabular}{|c|c|c|c|c|c|}
\hline & $T_{1}$ & $T_{2}$ & $T_{3}$ & $T_{4}$ & $T_{5}$ \\
\hline$X_{1}$ & $(0.7,0.6)$ & $(0.3,0.4)$ & $(0.4,0.3)$ & $(0.7,0.3)$ & $(0.6,0.3)$ \\
\hline$X_{2}$ & $(0.6,0.4)$ & $(07,0.5)$ & $(0.5,0.3)$ & $(0.6,0.2)$ & $(0.4,0.3)$ \\
\hline$X_{3}$ & $(0.5,0.3)$ & $(0.6,0.3)$ & $(0.4,0.2)$ & $(0.6,0.4)$ & $(0.5,0.4)$ \\
\hline$X_{4}$ & $(0.4,0.2)$ & $(0.7,0.4)$ & $(0.6,0.3)$ & $(0.2,0.5)$ & $(0.5,0.3)$ \\
\hline$X_{5}$ & $(0.5,0.4)$ & $(0.6,0.3)$ & $(0.4,0.2)$ & $(0.3,0.4)$ & $(0.4,0.4)$ \\
\hline$X_{6}$ & $(0.5,0.4)$ & $(0.8,0.4)$ & $(0.6,0.4)$ & $(0.4,0.3)$ & $(0.4,0.3)$ \\
\hline
\end{tabular}

Table 2. Decision matrix with q-ROFNs by the second expert

\begin{tabular}{|c|c|c|c|c|c|}
\hline & $T_{1}$ & $T_{2}$ & $T_{3}$ & $T_{4}$ & $T_{5}$ \\
\hline$X_{1}$ & $(0.7,0.5)$ & $(0.6,0.4)$ & $(0.4,0.3)$ & $(0.5,0.2)$ & $(0.5,0.3)$ \\
\hline$X_{2}$ & $(0.6,0.4)$ & $(0.7,0.5)$ & $(0.5,0.3)$ & $(0.5,0.4)$ & $(0.4,0.3)$ \\
\hline$X_{3}$ & $(0.5,0.3)$ & $(0.6,0.3)$ & $(0.5,0.1)$ & $(0.7,0.3)$ & $(0.5,0.4)$ \\
\hline$X_{4}$ & $(0.4,0.2)$ & $(0.7,0.4)$ & $(0.6,0.3)$ & $(0.2,0.6)$ & $(0.5,0.3)$ \\
\hline$X_{5}$ & $(0.5,0.3)$ & $(0.7,0.3)$ & $(0.4,0.2)$ & $(0.3,0.5)$ & $(0.4,0.4)$ \\
\hline$X_{6}$ & $(0.4,0.2)$ & $(0.5,0.2)$ & $(0.6,0.4)$ & $(0.4,0.3)$ & $(0.4,0.3)$ \\
\hline
\end{tabular}


Table 3. Decision matrix with q-ROFNs by the third expert

\begin{tabular}{|c|c|c|c|c|c|}
\hline & $T_{1}$ & $T_{2}$ & $T_{3}$ & $T_{4}$ & $T_{5}$ \\
\hline$X_{1}$ & $(0.5,0.3)$ & $(0.6,0.4)$ & $(0.4,0.3)$ & $(0.4,0.2)$ & $(0.5,0.3)$ \\
\hline$X_{2}$ & $(0.6,0.4)$ & $(0.4,0.2)$ & $(0.5,0.3)$ & $(0.6,0.4)$ & $(0.4,0.3)$ \\
\hline$X_{3}$ & $(0.5,0.3)$ & $(0.6,0.3)$ & $(0.7,0.5)$ & $(0.6,0.3)$ & $(0.5,0.4)$ \\
\hline$X_{4}$ & $(0.4,0.2)$ & $(0.7,0.4)$ & $(0.7,0.3)$ & $(0.6,0.2)$ & $(0.5,0.3)$ \\
\hline$X_{5}$ & $(0.5,0.3)$ & $(0.6,0.3)$ & $(0.6,0.3)$ & $(0.3,0.5)$ & $(0.4,0.2)$ \\
\hline$X_{6}$ & $(0.4,0.2)$ & $(0.5,0.4)$ & $(0.6,0.4)$ & $(0.4,0.3)$ & $(0.5,0.2)$ \\
\hline
\end{tabular}

\section{Algorithm one:}

If we use the q-ROFHA operator to fuse the given q-ROFNs, we can derive the aggregating collective matrix (see Table 4 ) and the position weight is $w=(0.2,0.5,0.3)$.

Table 4 . The aggregating matrix by q-ROFHA operator $(q=3)$

\begin{tabular}{|c|c|c|c|c|c|}
\hline & $T_{1}$ & $T_{2}$ & $T_{3}$ & $T_{4}$ & $T_{5}$ \\
\hline$X_{1}$ & $(0.6180,0.3734)$ & $(0.5438,0.4149)$ & $(0.3948,0.3148)$ & $(0.5283,0.2186)$ & $(0.5460,0.3148)$ \\
\hline$X_{2}$ & $(0.5928,0.4149)$ & $(0.6304,0.3620)$ & $(0.4937,0.3148)$ & $(0.5693,0.3037)$ & $(0.3948,0.3148)$ \\
\hline$X_{3}$ & $(0.4937,0.3148)$ & $(0.5928,0.3148)$ & $(0.5470,0.1945)$ & $(0.6297,0.3053)$ & $(0.4937,0.4149)$ \\
\hline$X_{4}$ & $(0.3948,0.2133)$ & $(0.6923,0.4149)$ & $(0.5225,0.3148)$ & $(0.3961,0.4334)$ & $(0.4937,0.3148)$ \\
\hline$X_{5}$ & $(0.4937,0.3402)$ & $(0.5925,0.3036)$ & $(0.4651,0.2623)$ & $(0.2960,0.4649)$ & $(0.3948,0.3513)$ \\
\hline$X_{6}$ & $(0.4281,0.2572)$ & $(0.6014,0.3169)$ & $(0.5928,0.4149)$ & $(0.3948,0.3148)$ & $(0.4247,0.2856)$ \\
\hline
\end{tabular}

Step 1: According to Table 4, we can compute $\mathrm{AS}_{h}(h=1,2,3,4,5,6)$ of every attributes.

$\mathrm{AS}_{1}=(0.5378,0.3200), \mathrm{AS}_{2}=(0.5514,0.3397), \mathrm{AS}_{3}=(0.5583,0.3003)$,

$\mathrm{AS}_{4}=(0.5314,0.3281), \mathrm{AS}_{5}=(0.4725,0.3382), \mathrm{AS}_{6}=(0.5083,0.3138)$.

Step 2: Compute the score values of $\mathrm{AS}_{h}(h=1,2,3,4,5,6)$.

$S\left(\mathrm{AS}_{1}\right)=0.1228, S\left(\mathrm{AS}_{2}\right)=0.1285, S\left(\mathrm{AS}_{3}\right)=0.1470$,

$S\left(\mathrm{AS}_{4}\right)=0.1147, S\left(\mathrm{AS}_{5}\right)=0.0668, S\left(\mathrm{AS}_{6}\right)=0.1004$.

Then, we can obtain the score of Table 4 (see Table 5) based on definition 2.

Table 5. The score matrix

\begin{tabular}{|c|c|c|c|c|c|}
\hline & $T_{1}$ & $T_{2}$ & $T_{3}$ & $T_{4}$ & $T_{5}$ \\
\hline$X_{1}$ & 0.1840 & 0.0894 & 0.0303 & 0.1370 & 0.1316 \\
\hline$X_{2}$ & 0.1369 & 0.2031 & 0.0891 & 0.1565 & 0.0303 \\
\hline$X_{3}$ & 0.0891 & 0.1771 & 0.1563 & 0.2212 & 0.0489 \\
\hline$X_{4}$ & 0.0518 & 0.2604 & 0.1114 & -0.0193 & 0.0891 \\
\hline$X_{5}$ & 0.0 .810 & 0.1800 & 0.0826 & -0.0745 & 0.0182 \\
\hline$X_{6}$ & 0.0614 & 0.1857 & 0.1369 & 0.0303 & 0.0533 \\
\hline
\end{tabular}


Step 3: According to score values, compute the PDAS (Table 6) and the NDAS (Table 7).

Table 6. The PDAS matrix

\begin{tabular}{|l|l|l|l|l|}
\hline 0.4986 & 0.0000 & 0.0000 & 0.1160 & 0.0718 \\
\hline 0.0654 & 0.5805 & 0.0000 & 0.2180 & 0.0000 \\
\hline 0.0000 & 0.2052 & 0.0636 & 0.5054 & 0.0000 \\
\hline 0.0000 & 1.2691 & 0.0000 & 0.0000 & 0.0000 \\
\hline 0.2124 & 1.6958 & 0.2364 & 0.0000 & 0.0000 \\
\hline 0.0000 & 0.8492 & 0.3633 & 0.0000 & 0.0000 \\
\hline
\end{tabular}

Table 7. The NDAS matrix

\begin{tabular}{|l|l|l|l|l|}
\hline 0.0000 & 0.2718 & 0.7529 & 0.0000 & 0.0000 \\
\hline 0.0000 & 0.0000 & 0.3063 & 0.0000 & 0.7639 \\
\hline 0.3935 & 0.0000 & 0.0000 & 0.0000 & 0.6672 \\
\hline 0.5483 & 0.0000 & 0.0288 & 1.1679 & 0.2232 \\
\hline 0.0000 & 0.0000 & 0.0000 & 2.1163 & 0.7277 \\
\hline 0.3881 & 0.0000 & 0.0000 & 0.6979 & 0.4691 \\
\hline
\end{tabular}

Step 4: Compute the positive weighted distance $\operatorname{SP}_{l}(l=1,2,3,4,5)$ and the negative weighted distance $\mathrm{SN}_{l}(l=1,2,3,4,5)$, where $\vartheta=(0.20,0.15,0.25,0.17,0.13,0.10)$,

$$
\begin{aligned}
& \mathrm{SP}_{1}=0.1371, \mathrm{SP}_{2}=0.6595, \mathrm{SP}_{3}=0.0830, \mathrm{SP}_{4}=0.1823, \mathrm{SP}_{5}=0.0144 \\
& \mathrm{SN}_{1}=0.2304, \mathrm{SN}_{2}=0.0544, \mathrm{SN}_{3}=0.2014, \mathrm{SN}_{4}=0.5434, \mathrm{SN}_{5}=0.4608
\end{aligned}
$$

Step 5: Normalize the values of $\operatorname{SP}_{l}(l=1,2,3,4,5)$ and $\mathrm{NP}_{l}(l=1,2,3,4,5)$ :

$\mathrm{NSP}_{1}=0.2079, \mathrm{NSP}_{2}=1.0000, \mathrm{NSP}_{3}=0.1258, \mathrm{NSP}_{4}=0.2763, \mathrm{NSP}_{5}=0.0218$;

$\mathrm{NSN}_{1}=0.4239, \mathrm{NSN}_{2}=0.1000, \mathrm{NSN}_{3}=0.3706, \mathrm{NSN}_{4}=1.0000, \mathrm{NSN}_{5}=0.8480$.

Step 6: Compute the values of $\operatorname{IAS}_{l}(l=1,2,3,4,5)$ :

$\mathrm{IAS}_{1}=0.3920, \mathrm{IAS}_{2}=0.9500, \mathrm{IAS}_{3}=0.3776, \mathrm{IAS}_{4}=0.1382, \mathrm{IAS}_{5}=0.0869$.

Step 7: Derive the ordering of $\operatorname{IAS}_{l}(l=1,2,3,4,5): \mathrm{IAS}_{2}>\mathrm{IAS}_{1}>\mathrm{IAS}_{3}>\mathrm{IAS}_{4}>\mathrm{IAS}_{5}$. We have: $T_{2}>T_{1}>T_{3}>T_{4}>T_{5}$. Thus, the best refrigerator is $T_{2}$.

\section{Algorithm two:}

If we use the q-ROFHG operator to fuse the given q-ROFNs, we can derive the aggregating matrix (Table 8 ) and the position weight is $w=(0.2,0.5,0.3)$. 
Table 8 . The aggregating matrix by q-ROFHG operator $(q=3)$

\begin{tabular}{|c|c|c|c|c|c|}
\hline & $T_{1}$ & $T_{2}$ & $T_{3}$ & $T_{4}$ & $T_{5}$ \\
\hline$X_{1}$ & $(0.6224,0.5112)$ & $(0.4850,0.4063)$ & $(0.4037,0.2990)$ & $(0.4936,0.2248)$ & $(0.5203,0.2990)$ \\
\hline$X_{2}$ & $(0.6031,0.3987)$ & $(0.5743,0.4368)$ & $(0.5035,0.2990)$ & $(0.5556,0.3769)$ & $(0.4037,0.2990)$ \\
\hline$X_{3}$ & $(0.5036,0.2990)$ & $(0.6031,0.2990)$ & $(0.5565,0.4294)$ & $(0.6200,0.3519)$ & $(0.5035,0.3987)$ \\
\hline$X_{4}$ & $(0.4037,0.1993)$ & $(0.7025,0.3987)$ & $(0.6355,0.2960)$ & $(0.2777,0.4931)$ & $(0.5035,0.2990)$ \\
\hline$X_{5}$ & $(0.5035,0.3519)$ & $(0.5807,0.2990)$ & $(0.4573,0.2592)$ & $(0.3036,0.4837)$ & $(0.4149,0.3643)$ \\
\hline$X_{6}$ & $(0.4202,0.2632)$ & $(0.5479,0.3379)$ & $(0.6031,0.3987)$ & $(0.4037,0.2990)$ & $(0.4378,0.2776)$ \\
\hline
\end{tabular}

Step 1: According to Table 8, we can compute the $\mathrm{AS}_{h}(h=1,2,3,4,5,6)$ under each attribute $\mathrm{AS}_{1}=(0.5173,0.3343), \mathrm{AS}_{2}=(0.5388,0.3578), \mathrm{AS}_{3}=(0.5629,0.3518)$, $\mathrm{AS}_{4}=(0.5570,0.3221), \mathrm{AS}_{5}=(0.4725,0.3438), \mathrm{AS}_{6}=(0.4982,0.3117)$.

Step 2: Obtain the score values of $\mathrm{AS}_{h}(h=1,2,3,4,5,6)$.

$S\left(\mathrm{AS}_{1}\right)=0.1011, S\left(\mathrm{AS}_{2}\right)=0.1106, S\left(\mathrm{AS}_{3}\right)=0.1348$,

$S\left(\mathrm{AS}_{4}\right)=0.1394, S\left(\mathrm{AS}_{5}\right)=0.0649, S\left(\mathrm{AS}_{6}\right)=0.0934$.

Then, we can obtain the score results of Table 8 (see Table 9) based on definition 2.

Table 9. The score results matrix

\begin{tabular}{|c|c|c|c|c|c|}
\hline & $T_{1}$ & $T_{2}$ & $T_{3}$ & $T_{4}$ & $T_{5}$ \\
\hline$X_{1}$ & 0.1075 & 0.0470 & 0.0391 & 0.1089 & 0.1141 \\
\hline$X_{2}$ & 0.1560 & 0.1061 & 0.1009 & 0.1180 & 0.0391 \\
\hline$X_{3}$ & 0.1010 & 0.1926 & 0.0932 & 0.1948 & 0.0643 \\
\hline$X_{4}$ & 0.0579 & 0.2833 & 0.2307 & -0.0985 & 0.1009 \\
\hline$X_{5}$ & 0.0841 & 0.1691 & 0.0782 & -0.0852 & 0.0231 \\
\hline$X_{6}$ & 0.0560 & 0.1259 & 0.1560 & 0.0391 & 0.0391 \\
\hline
\end{tabular}

Step 3: According to score values, compute the PDAS (Table 10) and NDAS matrix (Table 11).

Table 10. The PDAS matrix

\begin{tabular}{|l|l|l|l|l|}
\hline 0.0637 & 0.0000 & 0.0000 & 0.0000 & 0.7596 \\
\hline 0.5432 & 0.0000 & 0.0000 & 0.0000 & 0.0000 \\
\hline 0.0000 & 0.7420 & 0.0000 & 0.3973 & 0.0000 \\
\hline 0.0000 & 1.5620 & 0.7112 & 0.0000 & 0.5559 \\
\hline 0.0000 & 0.5291 & 0.0000 & 0.0000 & 0.0000 \\
\hline 0.0000 & 0.1385 & 0.1569 & 0.0000 & 0.0000 \\
\hline
\end{tabular}


Table 11. The NDAS matrix

\begin{tabular}{|l|l|l|l|l|}
\hline 0.0000 & 0.5749 & 0.7103 & 0.2187 & 0.0000 \\
\hline 0.2820 & 0.0407 & 0.2516 & 0.1536 & 0.3977 \\
\hline 0.0009 & 0.0000 & 0.3090 & 0.0000 & 0.0091 \\
\hline 0.4274 & 0.0000 & 0.0000 & 1.7066 & 0.0000 \\
\hline 0.1683 & 0.0000 & 0.4199 & 1.6112 & 0.6442 \\
\hline 0.4464 & 0.0000 & 0.0000 & 0.7197 & 0.0360 \\
\hline
\end{tabular}

Step 4: Compute the positive weighted distance $\operatorname{SP}_{l}(l=1,2,3,4,5)$ and the negative weighted distance $\mathrm{SN}_{l}(l=1,2,3,4,5)$, where $\vartheta=(0.20,0.15,0.25,0.17,0.13,0.10)$,

$$
\begin{aligned}
& \mathrm{SP}_{1}=0.1380, \mathrm{SP}_{2}=0.4662, \mathrm{SP}_{3}=0.1184, \mathrm{SP}_{4}=0.0556, \mathrm{SP}_{5}=0.1690 \\
& \mathrm{SN}_{1}=0.1539, \mathrm{SN}_{2}=0.0788, \mathrm{SN}_{3}=0.2896, \mathrm{SN}_{4}=0.7751, \mathrm{SN}_{5}=0.2557
\end{aligned}
$$

Step 5: Normalize the results of $\operatorname{SP}_{l}(l=1,2,3,4,5)$ and $\mathrm{SN}_{l}(l=1,2,3,4,5)$ :

$$
\begin{aligned}
& \mathrm{NSP}_{1}=0.2960, \mathrm{NSP}_{2}=1.0000, \mathrm{SNP}_{3}=0.2540, \mathrm{NSP}_{4}=0.1193, \mathrm{NSP}_{5}=0.3625 \\
& \mathrm{NSN}_{1}=0.1986, \mathrm{NSN}_{2}=0.1016, \mathrm{NSN}_{3}=0.3737, \mathrm{NSN}_{1}=1.0000, \mathrm{NSN}_{5}=0.3299
\end{aligned}
$$

Step 6: Derive the results of $\operatorname{IAS}_{l}(l=1,2,3,4,5)$ :

$$
\mathrm{IAS}_{1}=0.5487, \mathrm{IAS}_{2}=0.9492, \mathrm{IAS}_{3}=0.4401, \mathrm{IAS}_{4}=0.0597, \mathrm{IAS}_{5}=0.5163
$$

Step 7: Derive the ordering of $\operatorname{IAS}_{l}(l=1,2,3,4,5): \mathrm{IAS}_{2}>\mathrm{IAS}_{1}>\mathrm{IAS}_{5}>\mathrm{IAS}_{3}>\mathrm{IAS}_{4}$. We have: $T_{2}>T_{1}>T_{5}>T_{3}>T_{4}$. Thus, the best refrigerator is also $T_{2}$.

\section{Compared with exiting MAGDM methods}

To testify the advantages and effectiveness of q-ROF-EDAS method, we compare this method with some operators (Liu \& Wang, 2018). According to the results of Table 1 and the attributes weight $\vartheta=(0.20,0.15,0.25,0.17,0.13,0.10)$, we can compute the ranking of alternatives by these operators are listed in Table 12 .

Table 12. Ranking of alternatives by the some operators

\begin{tabular}{|l|l|l|}
\hline \multicolumn{1}{|c|}{ Methods } & \multicolumn{1}{|c|}{ The scoring function } & \multicolumn{1}{c|}{ Order } \\
\hline $\begin{array}{l}\text { q-ROFWA operator } \\
\text { (Liu \& Wang, 2018) }\end{array}$ & $\begin{array}{l}S_{1}=0.1246, S_{2}=0.1986, S_{3}=0.1462, \\
S_{4}=0.1364, S_{5}=0.0786\end{array}$ & $T_{2}>T_{3}>T_{4}>T_{1}>T_{5}$ \\
\hline $\begin{array}{l}\text { q-ROFWG operator } \\
\text { (Liu \& Wang, 2018) }\end{array}$ & $\begin{array}{l}S_{1}=0.0811, S_{2}=0.1445, S_{3}=0.0974, \\
S_{4}=0.0581, S_{5}=0.0653\end{array}$ & $T_{2}>T_{3}>T_{1}>T_{5}>T_{4}$ \\
\hline $\begin{array}{l}\text { q-ROF-EDAS method } \\
\text { with q-ROFHA operator }\end{array}$ & $\begin{array}{l}\text { IAS }_{1}=0.3920, \mathrm{IAS}_{2}=0.9500, \mathrm{IAS}_{3}=0.3776, \\
\mathrm{IAS}_{4}=0.1382, \mathrm{IAS}_{5}=0.0869\end{array}$ & $T_{2}>T_{1}>T_{3}>T_{4}>T_{5}$ \\
\hline $\begin{array}{l}\text { q-ROF-EDAS method } \\
\text { with q-ROFHG operator }\end{array}$ & $\begin{array}{l}\mathrm{IAS}_{1}=0.5487, \mathrm{IAS}_{2}=0.9492, \mathrm{IAS}_{3}=0.4401, \\
\mathrm{IAS}_{4}=0.0597, \mathrm{IAS}_{5}=0.5163\end{array}$ & $T_{2}>T_{1}>T_{5}>T_{3}>T_{4}$ \\
\hline
\end{tabular}


Comparing the results of the q-ROF-EDAS method with some existing operators, the aggregation results are slightly different. However, the best alternative is same. q-ROF-EDAS method has the precious characteristics of considering the conflicting attributes. And compared with other MAGDM methods, EDAS method has required fewer computations, although it results in the same best alternative. EDAS method is proposed based on the distance measure from the average solution unlike TOPSIS and VIKOR methods.

\section{Conclusions}

The q-ROFS provides a new way to accept information and make decisions. Its flexibility and convenience are more and more important in complex group decision making, with broad development prospects and far-reaching social significance. In our manuscript, we build the q-ROF-EDAS method for MAGDM. The specific content is as below: (1)Firstly, we review some basic knowledge of q-ROFNs. (2)Next, based on the q-ROFSs, we review and propose some aggregation operators, for example, q-ROFWA operator, q-ROFWG operator, q-ROFOWA operator, q-ROFOWG operator, q-ROFHA operator and q-ROFHG operator. (3)The q-ROFSs are a complex form of information expression. How to apply it effectively to our real society is a difficult problem. At present, the application on q-fuzzy sets is still relatively limited. In our manuscript, we build the q-rung orthopair fuzzy EDAS model for MAGDM and develop the computing steps for MAGDM problem with q-ROFNs. (4) Finally, in order to depict the effectiveness of proposed method, an example of purchasing refrigerator in case of sudden power failure is given. Moreover, to show the merits of this new model in detail, we compare proposed method with some existing methods. In our developed opproach, it's more accuracy and useful to consider the conflicting attributes.

Turning a complex, uncertain piece of information into an intuitive, easily-acceptable message is a very complicated task. In the future, more scholars will explore and expand to enrich the content of the q-ROFS and the q-ROF-EDAS method under other MAGDM and many other uncertain and fuzzy environments.

\section{Acknowledgments}

The work was supported by the National Natural Science Foundation of China under Grant No. 71571128 and the Humanities and Social Sciences Foundation of Ministry of Education of the People's Republic of China (No. 19YJA630056).

\section{References}

Bai, K. Y., Zhu, X. M., Wang, J., \& Zhang, R. T. (2018). Some Partitioned maclaurin symmetric mean based on q-rung orthopair fuzzy information for dealing with multi-attribute group decision making. Symmetry, 10(9), 383. https://doi.org/10.3390/sym10090383

Kahraman, C., Keshavarz Ghorabaee, M., Zavadskas, E. K., Onar, S. C., Yazdani, M., \& Oztaysi, B. (2017). Intuitionistic fuzzy EDAS method: An application to solid waste disposal site selection. Journal of Environmental Engineering and Landscape Management, 25, 1-12. https://doi.org/10.3846/16486897.2017.1281139 
Karabasevic, D., Zavadskas, E. K., Stanujkic, D., Popovic, G., \& Brzakovic, M. (2018). An approach to personnel selection in the it industry based on the EDAS method. Transformations in Business \& Economics, 17, 54-65.

Keshavarz-Ghorabaee, M., Amiri, M., Zavadskas, E. K., Turskis, Z., \& Antucheviciene, J. (2018). A dynamic fuzzy approach based on the EDAS method for multi-criteria subcontractor evaluation. Information, 9(3), 68. https://doi.org/10.3390/info9030068

Keshavarz Ghorabaee, M., Amiri, M., Zavadskas, E. K., \& Turskis, Z. (2017). Multi-criteria group decision-making using an extended edas method with interval type-2 fuzzy sets. E \& M Ekonomie a Management, 20, 48-68. https://doi.org/10.15240/tul/001/2017-1-004

Keshavarz Ghorabaee, M., Amiri, M., Zavadskas, E. K., Turskis, Z., \& Antucheviciene, J. (2017). Stochastic EDAS method for multi-criteria decision-making with normally distributed data. Journal of Intelligent \& Fuzzy Systems, 33, 1627-1638. https://doi.org/10.3233/JIFS-17184

Keshavarz Ghorabaee, M., Zavadskas, E. K., Amiri, M., \& Turskis, Z. (2016). Extended EDAS method for fuzzy multi-criteria decision-making: An Application to supplier selection. International Journal of Computers Communications \& Control, 11, 358-371. https://doi.org/10.15837/ijccc.2016.3.2557

Keshavarz Ghorabaee, M., Zavadskas, E. K., Olfat, L., \& Turskis, Z. (2015). Multi-criteria inventory classification using a new method of evaluation based on distance from average solution (EDAS). Informatica, 26, 435-451. https://doi.org/10.15388/Informatica.2015.57

Li, Z. X., Gao, H., \& Wei, G. W. (2018). Methods for multiple attribute group decision making based on intuitionistic fuzzy Dombi Hamy mean operators. Symmetry, 10(11), 574. https://doi.org/10.3390/sym10110574

Li, Z. X., Wei, G. W., \& Gao, H. (2018). Methods for multiple attribute decision making with intervalvalued Pythagorean fuzzy information. Mathematics, 6(11), 228. https://doi.org/10.3390/math6110228

Li, Z. X., Wei, G. W., \& Lu, M. (2018). Pythagorean fuzzy Hamy mean operators in multiple attribute group decision making and their application to supplier selection. Symmetry, 10(10), 505. https://doi.org/10.3390/sym10100505

Liang, D. C., Xu, Z. S., Liu, D., \& Wu, Y. (2018). Method for three-way decisions using ideal TOPSIS solutions at Pythagorean fuzzy information. Information Sciences, 435, 282-295. https://doi.org/10.1016/j.ins.2018.01.015

Liu, P. D., \& Liu, J. L. (2018). Some q-rung orthopai fuzzy bonferroni mean operators and their application to multi-attribute group decision making. International Journal of Intelligent Systems, 33, 315-347. https://doi.org/10.1002/int.21933

Liu, P. D., \& Wang, P. (2018). Some q-rung orthopair fuzzy aggregation operators and their applications to multiple-attribute decision making. International Journal of Intelligent Systems, 33, 259-280. https://doi.org/10.1002/int.21927

Mirghafoori, S. H., Izadi, M. R., \& Daei, A. (2018). Analysis of the barriers affecting the quality of electronic services of libraries by VIKOR, FMEA and entropy combined approach in an intuitionisticfuzzy environment. Journal of Intelligent \& Fuzzy Systems, 34, 2441-2451. https://doi.org/10.3233/JIFS-171695

Peng, X. D., \& Dai, J. G. (2017). Approaches to Pythagorean fuzzy stochastic multi-criteria decision making based on prospect theory and regret theory with new distance measure and score function. International Journal of Intelligent Systems, 32, 1187-1214. https://doi.org/10.1002/int.21896

Peng, X. D., Dai, J. G., \& Garg, H. (2018). Exponential operation and aggregation operator for q-rung orthopair fuzzy set and their decision-making method with a new score function. International Journal of Intelligent Systems, 33, 2255-2282. https://doi.org/10.1002/int.22028 
Stanujkic, D., Zavadskas, E. K., Keshavarz Ghorabaee, M., \& Turskis, Z. (2017). An extension of the EDAS Method based on the use of interval grey numbers. Studies in Informatics and Control, 26, 5-12. https://doi.org/10.24846/v26i1y201701

Stevic, Z., Vasiljevic, M., Zavadskas, E. K., Sremac, S., \& Turskis, Z. (2018). Selection of carpenter manufacturer using Fuzzy EDAS method. Inzinerine Ekonomika-Engineering Economics, 29, 281290. https://doi.org/10.5755/j01.ee.29.3.16818

Wang, J., Gao, H., \& Wei, G. W. (2019). The generalized Dice similarity measures for Pythagorean fuzzy multiple attribute group decision making. International Journal of Intelligent Systems, 34, 1158-1183. https://doi.org/10.1002/int.22090

Wang, J., Wei, G. W., \& Gao, H. (2018). Approaches to multiple attribute decision making with intervalvalued 2-tuple linguistic Pythagorean fuzzy information. Mathematics, 6(10), 201. https://doi.org/10.3390/math6100201

Wang, J., Wei, G. W., Lu, J. P., Alsaadi, F. E., Hayat, T., Wei, C., \& Zhang, Y. (2019). Some q-rung orthopair fuzzy Hamy mean operators in multiple attribute decision making and their application to enterprise resource planning systems selection. International Journal of Intelligent Systems, 34, 2429-2458. https://doi.org/10.1002/int.22155

Wang, P., Wang, J., Wei, G. W., \& Wei, C. (2019). Similarity measures of q-rung orthopair fuzzy sets based on cosine function and their applications. Mathematics, 7(4), 340. https://doi.org/10.3390/math7040340

Wei, G. W. (2019). Pythagorean fuzzy Hamacher power aggregation operators in multiple attribute decision making. Fundamenta Informaticae, 166, 57-85. https://doi.org/10.3233/FI-2019-1794

Wei, G. W., Gao, H., \& Wei, Y. (2018). Some q-rung orthopair fuzzy Heronian mean operators in multiple attribute decision making. International Journal of Intelligent Systems, 33, 1426-1458. https://doi.org/10.1002/int.21985

Wei, G. W., Wei, C., Wang, J., Gao, H., \& Wei, Y. (2019). Some q-rung orthopair fuzzy maclaurin symmetric mean operators and their applications to potential evaluation of emerging technology commercialization. International Journal of Intelligent Systems, 34, 50-81. https://doi.org/10.1002/int.22042

Wu, L. P., Wang, J., \& Gao, H. (2019). Models for competiveness evaluation of tourist destination with some interval-valued intuitionistic fuzzy Hamy mean operators. Journal of Intelligent and Fuzzy Systems, 36, 5693-5709. https://doi.org/10.3233/JIFS-181545

Wu, L. P., Wei, G. W., Gao, H., \& Wei, Y. (2018). Some interval-valued intuitionistic fuzzy Dombi Hamy mean operators and their application for evaluating the elderly tourism service quality in tourism destination. Mathematics, 6(12), 294. https://doi.org/10.3390/math6120294

Yager, R. (2017). Generalized orthopair fuzzy sets. Ieee Transactions on Fuzzy Systems, 25, 1222-1230. https://doi.org/10.1109/TFUZZ.2016.2604005

Yager, R. R. (2014). Pythagorean membership grades in multicriteria decision making. Ieee Transactions on Fuzzy Systems, 22, 958-965. https://doi.org/10.1109/TFUZZ.2013.2278989

Yang, W., \& Pang, Y. F. (2019). New q-rung orthopair fuzzy partitioned Bonferroni mean operators and their application in multiple attribute decision making. International Journal of Intelligent Systems, 34, 439-476. https://doi.org/10.1002/int.22060 